\title{
PATENTED PATTERNS: On the art and science of patterns. A critical inquiry.
}

\author{
Tincuta Heinzel \\ Loughborough University \\ School of the Arts, English and Drama \\ Epinal Way, Loughborough \\ Leicestershire \\ LE11 3TU, UK \\ tinca@textiltronics.com
}

\begin{abstract}
The present paper proposes a critical reflection on the existing relationship between patterns, algorithms and their patentable status. Based on a series of legal actions related to the use of patterns (Robert Lang against Sarah Morris, Mexican indigenous peoples against Isabel Marant, Apple patent on some gestures, etc.) it will analyse the already existing legal interpretations of what a pattern is and will discuss in which way these cases can establish a precedent for today's digitalized environments. Defined both as form of stylistic and cultural expression, as well as logical forms, patterns are becoming elements of high importance for the present digital modelization technologies (see, for example, pattern recognition algorithms). Therefore, the legal status of a pattern is becoming a field of political battle. Notions like author and collective author, cultural tradition and logical form, creative commons and intellectual property are at stake in this context. The implications are of social, political and economic importance and this paper will sketch out some of the short-comings when it comes to their use and application, their implicit ideologies, as well as arts and sciences disciplinary divisions.
\end{abstract}

Patterns. Patents. Digitalization. Algorithm. Intellectual Property, Open Source. Art and Science Legislation.

\section{INTRODUCTION}

A successful physicist, engineer, and R\&D manager, with more than 80 patents in his portfolio, Robert Lang is also an origami artist, being one of the first to marry the art of origami with mathematics. His work made him a valuable consultant "on applications of origami to engineering problems ranging from air-bag design to expandable space telescopes" (Lang 2018) and most recently nanodesign (Main 2014). Recently he filed for copyright infringement against the British artist Sarah Morris for the use of origami patterns, sometimes after changing the origami's colour theme, without obtaining permission or giving credit. The arguments he used for such a legal action are related to the nature of origami, an art in its own right and the nature of his research which is based on science training and the use of different materials (papers, software, etc.) already patented or object of copyrights. He also argues the difference between the traditional origami forms and the newest origami patterns (in his terms, almost $90 \%$ of today's origami patterns were produced by origami artists in the latest 50 years). Supporter of a re-enforced patent and copyright systems, Robert Lang's legal action forces us to re-consider the definition of art and patterns, the use of scientific methods as a form of artistic endeavour, and the relationship between the open source nature of traditional patterns and motifs and the modern copyright system.

Another case worthy of consideration in this context is related to the use of traditional patterns by fashion brands (see in this sense the legal action filed by a group of Mexican indigenous peoples against the use of their traditional motifs by international fashion brands (Larsson 2015). Questioning different practices of cultural appropriation, this action was acclaimed by anti-globalisation and anti-big industries movements, as forms of political interventions.

Moreover, following the development of its IPod devices, Apple applied and patented the use of certain gesture patterns, creating the precedents for the "privatisation of gestures". (Newitz 2013)

All these examples are relevant today in the context in which patterns are not seen any more as forms of 
pure expression and cultural creation, but also as tools of technological modelization (see Christopher Alexander's research in patterns language and its influence for interaction design theories, etc) (Alexander et.al. 1977).

This paper will discuss the above-mentioned examples to launch a debate related to the definition of patterns and their relationship to algorithms, their patentable status, the already existing legal interpretations, as well as to discuss the precedents set by recent legal cases that impact on today's over digitalised environments. The red thread of this investigation is to understand the instances that can influence the legal life of patterns and the way in which law can influence the development of our technologies.

\section{PATTERNS LEGAL ACTIONS CASES}

\subsection{Robert Lang against Sarah Morris}

Considered a leading figure of modern origami, Robert Lang describes himself as "one of the pioneers of the cross-disciplinary marriage of origami with mathematics" (Lang 2018). Author of several books on origami art and design, he is often invited to present papers on origami-math (Lang 2009) at mathematical and computer science professional meetings, he is also "one of the few Western columnists for Origami Tanteidan Magazine, the journal of the Japan Origami Academic Society" (Lang 2018).

In 2011, Robert Lang started a legal action against British contemporary artist Sarah Morris (Alberge 2011) accusing her of creating a series of paintings on the theme of origami in which, to cite Robert Lang:

\footnotetext{
"she took origami crease patterns by several international origami artists, changed the color scheme, made up her own names for them, and then sold and exhibited them internationally without obtaining permission or giving credit." (Lang 2011)
}

Together with other origami artists whose work was used as well, Robert Lang have filed suit for copyright infringement against Ms. Morris in Federal Court in Oakland, California (Lang 2013).

On his website, Robert Lang tries to justify his action by claiming first of all that "crease patterns have a beauty and interest far beyond their role within origami" and, therefore, that they can be considered as standalone artworks. Since himself and his colleagues have exhibited origami pieces in venues ranging from commercial galleries to modern art museums, he considers his works as artworks and origami as art.

Secondly, he justifies his action by the fact that under American copyright law, an artist has the right to control derivative works of their original creations. In his opinion, Sarah Morris's paintings are derivative works from the crease patterns he and his colleagues have developed. Under derivative works he assigns those works based upon original works, which use processes like colorization, as in the case of Sarah Morris's paintings, to change the original forms of an artworks. He also concludes:
"As the original artists, we recognize that copyright law gives artists substantial rights regarding use of their artwork. Although we published our crease patterns, that does not mean we gave up our ownership rights to the original art works we created." (Lang 2011)

As he claims in one of his earliest interviews with Cat Weaver (Weaver 2011a, 2011b), his personal practice differs from that of other origami artists by the fact he is interested in pushing the limits of complexity and realism to create new forms by using mathematical techniques, mathematical concepts and tools that most of the origami artists don't. In the same interview he also claims that crease patterns can be copyrighted because law protects "original works of authorship fixed in a tangible medium of expression, which can be perceived, reproduced, or otherwise communicated," including "pictorial, graphic, or sculptural works". In his words:

\footnotetext{
"Our crease pattern artwork meets that definition: they're original works of authorship (by us); they're fixed in a tangible medium of expression (paper and/or electronic media) that can be perceived, reproduced, and communicated; and they are pictorial and graphic works." (Weaver 2011a)
}

Still, in another interview published by The New Yorker in February 2007, Robert Lang states that origami:
"It's like math ... It's just out there waiting to be discovered. The exciting stuff is the stuff where you don't even know how to begin." (Orlean 2007).

By making these claims, Robert Lang acknowledged that origami can be also a mathematical, logical object that waits to be discovered. It is not even about a technical development, as it is about a scientific discovery which only make use of folding as tool.

Such a comment on origami translated the ambiguity of origami's nature. Origami can then be both a mathematical object, as well as an artwork in its graphical and pictographic representations. More 
precisely, origami is a mathematical object by process, through the use of mathematical concepts and techniques for the accomplishment of an origami sculpture, and an artwork in its representation and the fixation of the process through origami sculptures and crease patterns.

Moreover, we will find origami not only in commercial art galleries or modern art museums, but also in science laboratories. As already mentioned, Robert Lang is also invited as consultant in a series of scientific enterprises which range from air-bag design to expandable space telescopes or nanodesign. In this case, the folding is perceived as a technical contribution and has been patented (see, for example, his participation in the CCMR 2017 Annual Symposium at Cornell University). These patents are most of the time resulting from research projects which are normally financed by national research agencies or corporations.

The case had been vividly discussed in different forums. In a blog note from 2011, Greg Allen argues that if we are comparing side-by-side Robert Lang's origami crease designs with Sarah Morris's origami paintings, then the size of the pictures is misleading us. His main argument is that in spite of the fact that Sarah Morris' works have created competition for plaintiffs by occupying a market for painted versions of their origami copyrighted artworks:

\begin{abstract}
"Morris has publicly discussed and presented her origami paintings as commentary both on origami and its history and its specific meanings and contexts, but also on its contemporary connection to science and systems... I still think they're wrong as hell, though, and that this case is a dangerously unproductive nuisance." (Allen 2011).
\end{abstract}

In the same vein, Joy Garnett comments, from a juridical point of view, the definition of derivative work. For him the origami artists confuse "derivative works" with "transformative" ones. And it comes once again to the nature of origami and crease pattern designs, which:

\begin{abstract}
"are functional diagrams made for the purpose of making 3D objects. Sarah Morris, a wellestablished painter, used them comically as compositional devices for flat paintings, the purpose of which is to comment ironically on the nature of flatness in painting. Morris's use of color schemes also nods (or genuflects deeply) to the paintings of Frank Stella; hence they function as both painting and jocular conceptual collage." (Garnett 2011).
\end{abstract}

What Joy Garnett states here, is the difference between the diagram of an algorithm and a pattern, but also between a contemporary art approach, defined both in terms of "image" and "conceptual comment" and an art production that it is not part of the contemporary art circuits. From an art theory's perspective, this position brings also into discussion George Dickie's 1970's concept of "world of art" seen as institutional authority over what can be of art and what cannot. It is "of art" something that it is part of the art world. And obviously, in spite of being exhibited in commercial art galleries, it could be argued that Robert Lang's origami aren't part of the mainstream contemporary art world. The legal action is, from this perspective, a clash between different "art worlds", where we are dealing with different forms of validation and authority, and with different financial gains.

In another commentary published in The Observer, Dan Duray uses Sarah Morris's comments related to her artistic practice:

\section{"I use all types of things in my work," she said. "Industrial design, mapping, instructions, geometry-I am creating a physical space in these paintings." (Duray 2013).}

In Duray's view she already flirted with appropriation of different works and media, like building designs, the cover of Roxy Music's The Atlantic Years in various pieces. Citing Sarah Morris again:

\begin{abstract}
"I never thought for a moment that I couldn't use this as a touchstone or as a launch pad for my work." "And basically," she added, "it's a spatial algorithm, which of course my paintings are not. They're flat. They're known for their flatness. They're known for their color. So, to me, phenomenologically, they're completely and utterly different. Did I use their work? Absolutely. You know? So, I never contested that I had used it. It was more like: do I have the right to use it?" (Duray 2013).
\end{abstract}

In these terms, it is obvious that the ambiguous nature of origami is open up to interpretation. Are origami "spatial algorithms" or "designed crease patterns" to be judged only from a formal point of view?

Even though Robert Lang's action against Sarah Morris seems to have been financially motivated (Duray 2013), it still raises a series of questions related to the legal interpretation of art and science works. Where does science stops, and art starts? And finally, what is art and what is science and what are the legal implications of these disciplinary divisions? Or even more precise, when it is of art and when it is of science? These questions are not anodyne, and they are bringing into the debate a large corpus of aesthetics and epistemology literature that seems to be suddenly simplified by a legal interpretation to the visual form. The court seems to ignore the last 100 years of aesthetic and artistic questioning related to the nature and the status of an artwork. Supporting the formal similitude between the two works, the legal action dissolved 
the tradition of "conceptual" comment opened by Marcel Duchamp and his ready-made objects interventions. From this perspective, Robert Lang and his colleagues' legal action seems a zealous act of someone who doesn't seems to be concerned by the enunciative conditions of an artwork (Danto 1973, De Duve 1994), by the fact that the meaning of an artwork can be shaped not only by the object and its technique, but also by the context and the modality in which it is exhibited. Unfortunately, the ambiguity of the nature of origami and the rather equivocal response of Sarah Morris to Robert Lang's allegations have created the precedent for a limitation of art's critical comment, one that tests the technical and formal conventions of a cultural context.

Robert Lang against Sarah Morris case is also illustrative for some of art and science intersections. The use of scientific visualization tools "to share the beauty of nano-world" (Orfescu 2016), or the considerations related to the fact that art and design should be mediators of scientific advancements (Malina 2010) are two of the most encountered positions. Still, there is another one, one which considers that the role of the art is to be a critical investigator of our techno-scientific, institutional and social configurations (Shaw 1999). It is this position which should be, in our opinion, cherished. The questions we have to face when it comes to legal aspects then is to know how to make possible such interventions, how to advance a legal environment that will not sabotage art's critical interventions while, at the same time, will support the effort of original creators? As it is also to question how, in our hyper-specialized era, it is still possible to ponder over the social and political implications of our cultural, scientific and technological developments? Who has the authority to do that? And what kind of instances are to be brought into dialogue?

\subsection{Indigenous Mexican Community against Isabel Marant}

In 2015 an indigenous Mexican community started a legal action against the French designer Isabel Marant. Presenting her spring-summer 2015 collection as "tribal without being too literal" Isabel Marant used almost unchanged the patterns and graphic elements of this indigenous community. She sold her pieces for $£ 200$ (the equivalent of 4.500 Mexican pesos), while the community was selling their original blouses for about 300 pesos. In a public declaration following the launch of the legal action, the representatives of Impact NGO, who supported the action, were pointing to the fact that Isabel Marant's designs are not an original work, as it is normally expected from a designer, but it is about plagiarism of graphical elements specific to the Tlahuitoltepec culture,

"a design which has transcended borders, and is not a novel creation as is affirmed by the designer." (Larsson, 2015).

In her paper, the Guardian's journalist Naomi Larsson mentions that the legal action of the indigenous Mexican community against Isabel Marant it is not an isolated case. For several such cases of cultural appropriation from cultures around the world legal actions have been launched, Victoria's Secret Native American-inspired feathered headdress, or Paul Smith modified scarf from Peshawari chappal (Pakistan), to name but two.

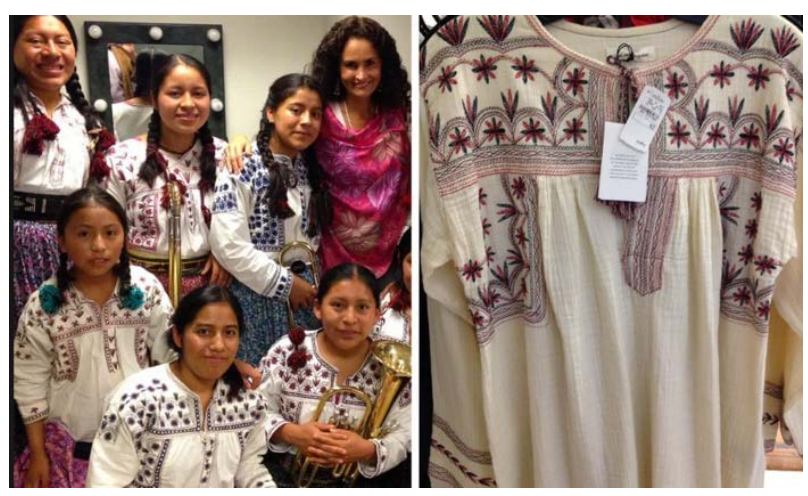

Figure 1: The pictures that were tweeted by musician Susana Harp. On the left, Harp, with the women of Tlahuitoltepec. On the right, the blouse from Marant's collection. Photograph: Courtesy Susana Harp. Source:

The Guardian: https://www.theguardian.com/globaldevelopment-professionals-

network/2015/jun/17/mexican-mixe-blouse-isabel-marant

Generally, these legal actions are acclaimed by antiglobalisation and anti-big industries movements, as forms of political actions that provide to a powerless indigenous minority in its fight with big corporations and Western multinational enterprises. It is about a historical justice into a globalized world.

We also have not to forget that there are different intellectual property law systems in the world (see, for example, the difference between the AngloSaxon copyright system and the German Urheberrecht, author's right system (Deterding et al. 2013)), with their complexities which make difficult for indigenous people to accede to fair legal representation. It is where the necessity for legal support from NGOs is vital. 


\subsection{Maasai Trademark against Louis Vuitton, Calvin Klein and Jaguard Land Rover, etc.}

Examples of such types of action are the initiatives established to protect the Maasai culture and identity. Legal entities like Maasai Intellectual Property Initiative Trust or Maasai Association for Preserving and Celebrating Maasai Cultural Heritage, have open legal actions against the misuses of this culture's patrimony and are fighting to protect them again the use of their cultural identity for commercial purposes. They opened in this sense a series of campaigns against companies like Louis Vuitton, Calvin Klein or Jaguard Land Rover, who were using the image of Maasai warriors to sell their products (Pilling 2018).

They also fight against "white saviours" like Mindy Budgor who describes herself a Maasai "princess warrior", traveling the world to collect money to build schools and hospitals in Kenya. Some of her opponents (Kachipanda 2013) were criticizing the fact she has create a label for herself, posing for fashion journal like Glamour and selling an exaggerated and distorted image of the Maasai patriarchy to justify her campaign, while completely neglecting the Maasai's women initiatives for emancipation.

From a juridical point of view, the different initiatives to protect against the abusive use the Maasai culture brings under the same umbrella the copyright law (aiming to cover their artistic, cultural and literary creations), as well as the trademarks (designed to protect the holder's commercial reputation) (Mackeay, 1999). The creation of Maasai Intellectual Property Initiative Trust is an initiative that aim to establish Maasai ethnographic culture as a trademark and to protect it against commercial use by others. They intend in this sense to enlarge the use of this trademark to protect Maasai farmers' premium coffee.

When it comes to the use of Maasai woven patterns, the issues are a little bit more complex to deal with. Weaving was one of the first crafts used for thousands of years in different parts of the globe. Based on mathematical and logical structures, some of the traditional woven patterns are similar in different cultures. It is enough to compare Maasai woven patterns with Scottish woven structures to easily recognize the similarities. There are, of course, variations in terms of colour, or proportions, but there are also structures that are ubiquitous. From this point of view, we can speak of woven structures as ethno-mathematics (Gilsdorf 2015). Like in the case of origami, weaving is about logical structures, and like in the case of origami, if we consider them as mathematical structures, it is important to notice that abstract ideas, such as mathematical formulae, scientific theories or even some literary creations, cannot be covered by intellectual property rights (Mackeay, 1999). Moreover, being the result of a "collective author", it makes difficult to set the authorship of these traditional patterns, as it is difficult to understand their symbolism out of their cultural context.

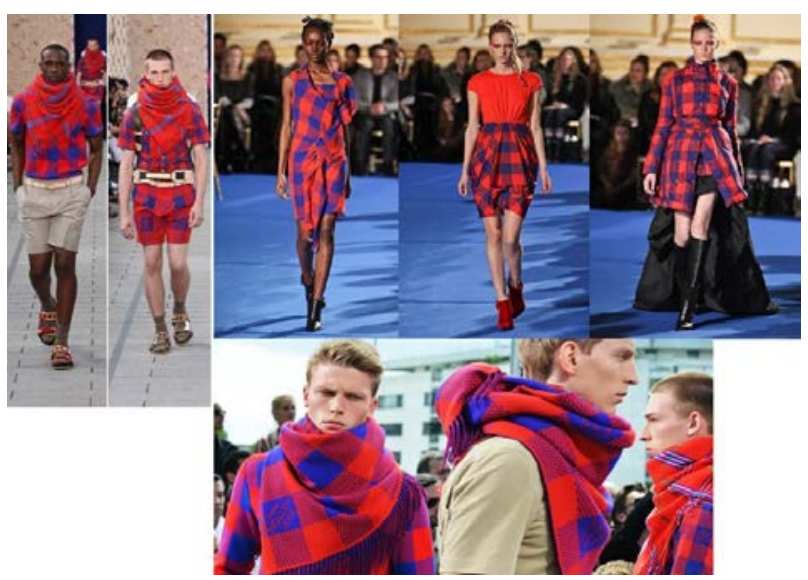

Figure 2. Louis Vuitton 2012 Summer/Spring collection inspired by the Maasai designs. Source:

https://face2faceafrica.com/article/kenyas-maasai-tribe-gettingpaid-use-traditional-designs

We should also note that some of those who support the indigenous communities are also supporters of free culture movements and communalism. As Kathy Bowrey and Jane Anderson (Bowrey \& Anderson 2009) have shown, the defence of indigenous population rights is quite complex and cannot be done out of historical and colonial considerations. As they stated:
"The ethos of freedom, public, openness and commons is problematic because it does not properly deal with the baggage of the past. For many Indigenous people across the globe, there is no fuzzy, warm glow that automatically accompanies western words like humanity, culture, progress, freedom, openness, knowledge. For Indigenous people living in Australia there is no automatic sense of entitlement or inclusion that comes with notions of 'the public', the 'public good' or 'the public interest. These idealistic political and cultural concepts were, and arguably still are, largely experienced by Indigenous people as terms of exclusion." (Bowrey \& Anderson 2009, p.480).

This is to say that the local, regional or national differences are seldom articulated within national or international discourses on intellectual property.

Moreover, as Bowrey \& Anderson equally mention, and as it was previously discussed by the French anthropologist Claude Levy-Strauss (Levy-Strauss 1962), there are difficulties to legitimatize the indigenous communities' knowledge by an international scientific community. How then it is 
possible to patent possible technical solutions if the references and the value systems are different?

\subsection{Apple Gesture Patents}

Leading the commercial development of tactile technologies, Apple had patented a series of multitouch gesturing patterns. They are not the only ones to have done so. As Annalee Newitz (Newitz 2013) pointed out, the tech companies have patented gestures for almost two decades now.

There exists also a precedent in the patenting of gestures in Martha Graham's company filling for copyrights of many of her iconic dances. Still, when it comes to gesturing in relationship with the technical devices, the question is what exactly has been patented. Is it the gesture in itself (the particular coordinated bodily movement)? Or the mapping technique which aim to acquire the traces left by gestures in relationship to future technical devices?

Patenting a gesture forces us to take into discussion the nature of interactive creations, as well as the execution of these gestures (or, in other words, the use of these interactive devices). It is supposed that certain gestures that have been patented are now in the property of Apple (Newitz 2013). Does it mean that in the future I might be limited in performing these gestures? Are they gone compose a gestures vocabulary allowed to be used only by those who bought Apples devices? Would that create a social and cultural barrier? These are just some of the questions the patenting of gestures pushes us to raise. Once again, there is an ambiguity of what has been patented.

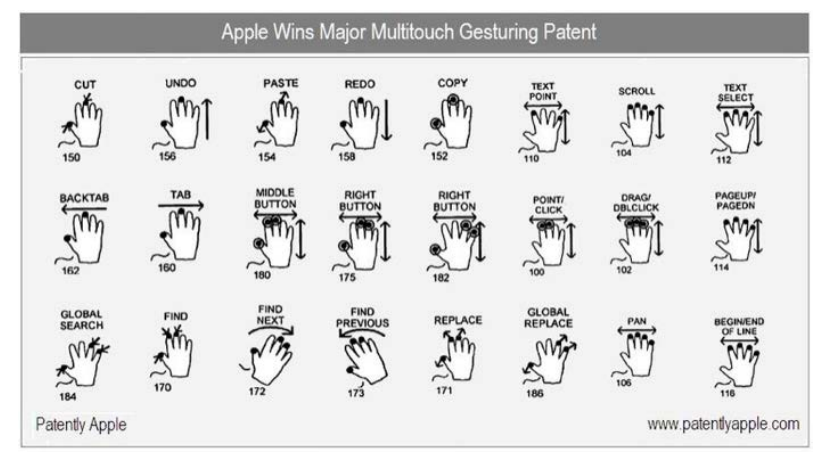

Figure 3: Drawings from Apple Multitouch Gesturing Patent. Source: https://cvil.ly/newly-approved-applegesture-patent-b2be8e545f62

Since in order to development such devices, usercentered approaches have been primarily used, one should also ask: Should the users also be questioned when concerns related to the legal status of gesture are raised? Should we grant the users with the same powers when it comes to the design of a legal system related to gestures, as design thinking methodologies (Simon 1996,
Waloszek 2012) have encouraged them to participate in the design processes of interactive systems? The democratization of design processes (Heinzel 2016), so much praised in the interactive design contexts, should be also enlarged to the decisions related to the legal fate of the interactive patterns? Why not, one might answer!

\subsection{Hannah Perner - Wilson against Electronics and Telecommunications Research Institute, Daejeon (KR) and Georgia Tech Research Corporation, Atlanta, GA (US)}

In a recent tweet, Hannah Perner-Wilson (PernerWilson, 2018), leading figure of e-textiles scene, had shown her concern related to a patent awarded in 2016 (US Patent 2016) to Hyung Sun Lee, Daejeon (KR); Hyung Cheol Shin, Daejeon (KR); Thad E. Starner, Atlanta, GA (US); Scott M. Gilliland, Atlanta, GA (US) and Clint Zeagler, Atlanta, GA (US) from the Electronics and Telecommunications Research Institute, Daejeon, Korea and, respectively Georgia Tech Research Corporation, Atlanta, USA, for a version of an e-textiles tilt sensor she had designed back in 2009 during her master studies at MIT. Her tilt sensor construction kit has been released by her into the open public domain and had made the object of a series of improvements over time (Perner-Wilson 2009).

It is not that the patent is ignoring Hannah PernerWilson's work. On the contrary, the patent mentions her scientific contribution (a conference paper published in 2011) (Perner-Wilson et.al. 2011) and credit her for her previous "art creations". But in doing so, the patent introduces a difference between an art creation and a design / technical solution, where the main difference relies in the fact that Hannah Perner-Wilson's Instructables webpage (Perner-Wilson 2009) attempts to deliver information for a DIY makers' scene, while the patent seekers are concerned to appropriate for themselves the industrial and commercial potentials of the sensor's pattern's construction. The patent gives credits for the type of sensor, the materials used and the sensor's methodologies of construction (in other words, the design). And by doing so, not only that they appropriate for themselves an "art creation" in order to use it for commercial purposes, but they also limit the author of the e-textiles tilt sensor to develop her creation out of on art endeavour. In her tweet, Hannah Perner-Wilson is clear about the fact that:

"the patent does not cover my version of the design. It builds off it, even references it and introduces a technique for using it upside down with capacitive sensing. What upsets me is to see work intended as part of an open and collective design process, feed into a system that restricts replication and development by everyone." (Perner-Wilson 2018) 
The present case shows how the different modalities of the intellectual property are overlapping (in this case the copyright and the patent) and how these breaches in the legal system can be exploited. The patent's authors are obviously not on the same value page with the initial creator of the tilt sensor. And the question is how can we provide justice for the original creator of the tils sensor? How we can respect her choices to keep the development of the sensor in the open public domain? What kind of instruments and tools of legal intervention are we ready to arm ourselves in the competition between different values' and philosophies of the legal system?

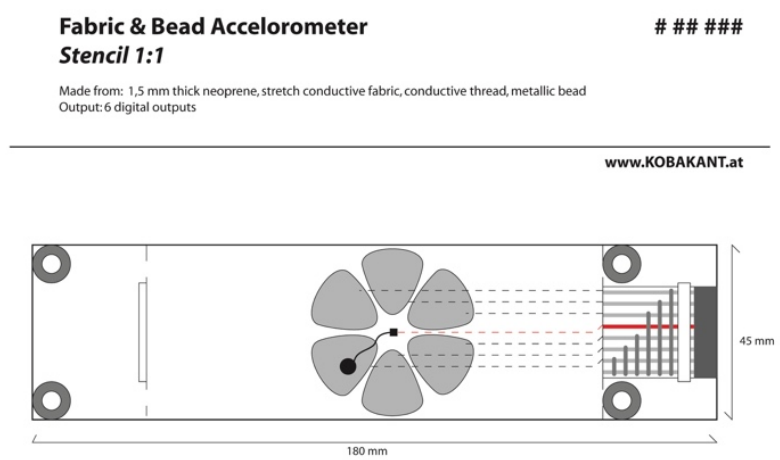

Figure 4: Hannah Perner-Wilson's tilt sensor diagram. (Courtesy: Hannah Perner-Wilson)

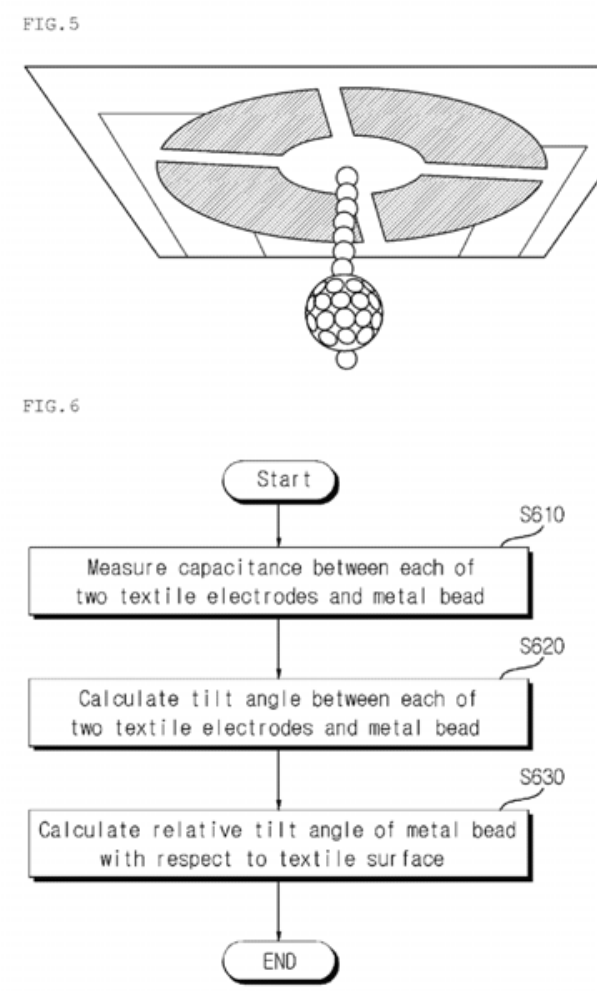

Figure 5: Figure from the US US9316481B2 Patent Sensor for measuring tilt angle based on electronic textile and method thereof (Source: https://patents.google.com/?q=tilt\&q=sensor\&assignee= Georgia+tech\&oq=tilt+sensor+Georgia+tech)

\section{PATTERNS AND ALGORITHMS}

As the cases presented earlier show us, the notion of pattern goes beyond the common understanding of a designed pattern. A pattern nowadays can be a formal configuration, as well as the description of a physical law or the transcription of a method or of a time-based form.

As a law of nature, a pattern cannot be subject of a copyright law. Described in scientific papers and sometimes assigned to scientists' names, the laws of nature are associated with pioneering approaches that lead to scientific discoveries. The authorship in this case is related to the originality of scientific approach, the experimental set up and the novelty of the results (Schneider 2018). Given the high degree of technical mediation in the experimental settings, there is no doubt nowadays that these approaches are interdependent of the technical developments (Allamel-Raffin 2010). It is why we have to refer to nowadays scientific research as techno-scientific developments and aggregates (Klein 2005). It is also from where resides the difficulty of the legal aspects related to science.

As a graphic element, a pattern is the result of the work of an author to which one can acknowledge the authorship. It is generally a form of expression, made possible by its transposition into a media. Some patterns can also be the result of joint authorship, as is the case of indigenous cultures' patterns. Appropriated and acknowledged by different communities, they become significant signs of these communities, having most of the time a role in their culture's semiotic constructions. It is their cultural circumscriptions which help them to become actants in cultural and social orders.

The origami crease patterns are patterns of another kind. They translate in graphical and pictorial form a method or principle of construction. They are in this sense the expression of an abstract, yet performative form. As a logical object, they cannot be attributed copyright. Still, there is an ambiguity between the nature of the pattern and its graphical representation. This ambiguity is visible in Robert Lang against Sarah Morris legal action.

The situation is similar when it comes to the gesturing patterns. Besides being an element of the development of interactive devices and interfaces, the gesture is a performative act. As a performative act of the body, the gestures can also be part of what Marcel Mauss (Mauss 1936) has defined as the "technologies of the body". Not only they have a functional role in the execution of different tasks, but 
they can be cultural defined and transmitted. "Physio-psycho-social" forms of human acting, the techniques of the body are socially modelled and culturally interpreted. The privatization of the gestures, as made possible by Apple's gesturing patents, interfere then not only with the ergonomic aspects of a device, but also with the cultural and semiotic stances of the body. The implications are therefore not only of technological nature, but also of social and cultural nature.

Hannah Perner-Wilson's authorship of the tilt etextiles sensor pattern also brings into attention the fact that same patterns can be assigned both to the art field and the technical field. The ambiguity of the field's assignation creates breaches in the legal system and overlook the original work's values reference system. The case of the tilts sensor shows in which way the co-existence of two competitive IP systems has to be all the time negotiated and defended.

The performativity of patterns is what brings patterns and algorithms together. Defined as methods of accomplishing different tasks, the algorithms are operative modes which makes use of patterns to assign the reality.

It was the research of architect Christopher Alexander on the "patterns language" that open the space for the integration of patterns into interactive design research. In his book from 1977 on towns, buildings, constructions, Alexander advances 253 patterns, which all together "form a language." (Alexander, 1977). This language was supposed to take into account the way the people are living, the way they communicate about the spaces they are living in. For Alexander therefore, the patterns describe a problem and then offered a solution, they are "timeless entities", while a pattern language has the "structure of a network" and allows the communication in architectural terms between all the people that are sharing a common space. For small social units (families, workgroups, gatherings etc.), for example, the patterns are:

- the family,

- the house for a small family,

- the house for a couple,

- the house for one person,

- your own home.

For a philosophy of structure, the plans and the conception of the buildings should consider:

- structure follows social spaces,

- efficient structure,

- good materials,

- gradual stiffening.
And the list can continue like this. Alexander's patterns language can be in this sense considered one of the first books write as a generative grammar for architecture.

Another architect can also help us to understand the relationship between performance and notation. Bernard Tschumi's "The Block. Manhattan Transcripts" (Tschumi, 1980), uses the cinematic transcriptions to develop architectural interventions into the city. Taking as starting point not the building, but the movement into the space, Tschumi's notations constitute an architectural language that use performance to make operational an architectural project.

It is known that the intellectual property laws protect applications of ideas and information which has commercial value. The legal interpretations of the status of patterns has the capacity to interfere in the way we communicate and the way we perform in social contexts. But there are a lot of ambiguities when it comes to the nature of patterns and the most appropriated way to legally define and approach them.

\section{ON INTELLECTUAL PROPERTY}

Arriving at this point we see ourselves obliged to investigate a little bit more the conditions under which the intellectual property laws are making sense of patterns.

As some authors have shown (Mackeay 1999), the intellectual property laws are originating in the privileges granted by emperors, kings, and princesses once with the Renaissance. These privileges were rewarding creative efforts or special skills, but also regulations of an industry, providing in this way revenue for the rulers (see, for example, French monarchy's tapestry workshops). The modern intellectual property laws are often seen as the modern guise of these revenue seeking interventions.

Deployed as copyrights for artistic and cultural creations, as trademarks to protect the holder's commercial reputation, as patents for industrial inventions and innovative solutions, as industrial designs for industrial innovations, or as designs where the form, the shape, the colour and the proportions count, the intellectual properties laws aim to encourage the creators to develop ideas, products, and to put them in suitable form for public consumptions. Their role is to financially protect the creators' investment of time and resources. Like all property rights they are transferable, but contrary to the normal property rights, they are limited in time. Still: 
"none of them, however, protects abstract ideas as such, as in mathematical formulae, scientific theories or plots of literary creations. In each case, a particular expression, design, or embodiment is protected." (Mackeay 1999, p. 423).

The failures and the ambiguities of the intellectual property laws (Schneider 2018) made over time critics to speak against the limitations of their system (Drahos 1996). For them, the IP laws are reserving an intangible object to one person, excluding others from it, while most advances in science, technology and social organizations are built upon earlier information. An IP law might reward the first inventor, but at the same time inhibit the followers who could better develop the original idea. Free Software (Free Software Foundation 1996) and Open Source Software movements are trying to offer alternatives to IP system, embracing positions with different outcomes. While the Free Software movement promotes the universal freedom to study, distribute, create, and modify any technical realizations, for the Open Source movement adherents, the copyright holder provides the rights to study, change, and distribute the software to anyone and for any purpose. For both of them the idea of open access and collaboration is central.

Another critical aspect of the patent system is related to its fragmentation, which makes impossible the establishment of efficient and affordable lines of exploitation of technical inventions. The interdependency between different parts that are composing a technical system and their assignment to different authors are factors that can block the innovation. Therefore, there is no evidence that an enforced intellectual property law is supporting innovation (Walker 2015).

Most of the authors concerned by intellectual property laws agree on the fact that there should be a balance between the protected and the free of flow of information. For someone as Peter Drahos (Drahos 1996) property - even in its abstract form of intellectual property - is an institutional shell which covers a set of relations that are historically and culturally dependant. Since there is no essentialist truth about property, he encourages an instrumental approach of the IP law, one which endorses the social costs of intellectual properties. Such an approach should change the focus from privileges to duties. Performative in its nature, an instrumental approach of the IP law:

"begins to investigate the contingent connections and processes that exist between property and individual behaviour and choice, between property and the formation of groups and factions, between property and power, between property and patterns of economic growth and development, and between property and the social patterns and organisations it gives rise to, as well as the way in which property comes to be patterned and shaped by social organisations." (Drahos 1996, p.252)

\section{LAW, JUSTICE AND POLITICS}

To repair a legal system like that of intellectual property, one should investigate both the way in which a law is designed and the way in which it is applied. As we saw, the law is a protocol that allows a society to function.

As Carl Joachim Friedrich had shown already in 1958 (Friedrich 1958), from a historical perspective, the philosophy of law had always gravitated around certain problems that recur again and again. The central one is that of justice towards which all laws should attempt. But justice is a dynamic process that takes place in the political frameworks and it is dominated by the forces that are composing the political spectrum. In conjunction with the problem of justice, the idea of equality crosses like a red thread the whole history of discussions around justice. If one admits that everybody ought to be equal to each other and therefore in front of the law, the question of equality is transferred in the political realms. As Hannah Arendt (Arendt 1958) had shown, the essence of the politics is the debate and the necessary negotiations between different parts. To create the grounds for justice to be addressed, one should relate to a complex value system of an individual, a community or mankind.

Moreover, the interdependence between law and justice creates the problem of authority. Authority is of importance for both the legal and social order. In the social order there is a difference between legitimacy and legality. Not everything that is legal finds a moral legitimacy. The case of Hannah Perner-Wilson against Electronics and Telecommunications Research Institute, Daejeon, Korea and, respectively, Georgia Tech Research Corporation, Atlanta, USA, is illustrative in this sense.

Still, if we are to embrace Carl Joachim Friedrich's perspective we should avoid to base authority upon legitimacy.

"The will of those who participate in the community's common concerns must be augmented not only by those who are "learned in law" but also by those who know about right and justice. What this means is that the will even of the majority must be related to the higher reason of a system of values - values that are not seen as purely subjective preferences." (Friedrich 1958, p.203)

In the case of the patterns, both the individual and the collective values are presented. The legal actions analysed here have all addressed in one 
way or another the issues related to the notion of justice. As practitioners and users of interactive systems, we have to pay attention to the legal status of patterns, and their performative counterpart, the algorithms, to amend them and to debate them. It is only in this way we can find justice in the different confrontations we are most likely to face in this age of overwhelming digitalization.

\section{CONCLUSIONS}

In the age of interactivity, a pattern it is not only a "timeless entity", to use Christopher Alexander's definition, but can also be the notation of a performative and operational intervention, in other words of an algorithm. An algorithm is the performative side of a pattern and therefore its importance has become crucial in the digital age. The overwhelming presence of digital and interactive structures in the daily life implies a careful consideration of the legal status of patterns. Therefore, the legal definition of a pattern it is not neutral. There are also a series of ambiguities when it comes to define and to apply the legal status of a pattern, as there are breaches into the system.

In all the studied examples of legal actions, the idea of justice, and moreover the idea of economic justice, was presented in one form or another. As has been shown the issues are complex and they can vary from one context to another. The disciplinary demarcation between art and science, the definition of a pattern or of an author plays a role in the attribution a pattern can gain in the frame of the intellectual property laws. These attributions have social and economic implications. It is why it is very difficult for any law system to be detached from politics.

Today highly specialized disciplinary demarcations, the ambiguity of certain cases, ask for a debate where the specialized and less specialized voices, the different value systems should have an intervention. The way in which an art critical intervention is authorized, the way in which our gestures are socially and technically assigned, the way in which our patent system is re-balanced, cannot be achieved other than by political address.

\section{ACKNOWLEDGEMENTS}

I would like to thank the reviewers of the conference, Adrian Freed and Terence Kavanagh for reading and for giving feed-back on this paper.

\section{REFERENCES}

Alberge, D. (2011). Tate Artist Sarah Morris 'Unfolded' our Works, Claim Leading Origami
Designers, in The Guardian, URL: https://www.theguardian.com/artanddesign/2011/ju n/05/tate-artist-sarah-martin-origami-lawsuit. (retrieved 15 June 2018).

Allamel- Raffin, C. (2010). Le texte et l'image dans la formulation de la preuve en physique des materiaux, Revue d'anthropologie des connaissances, No.3/2010, 476-504.

Arendt, H. (1958). The Human Condition, Chicago: University of Chicago Press.

Bowrey, K.\& Anderson, J.E. (2009). The Politics of Global Information Sharing, Social and Legal Studies, Vol. 18, Issue 4, URL: http://works.bepress.com/jane anderson/4/ (retrieved 15 June 2018).

CCMR 2017 Annual Symposium. Atomic Origami: A technology Platform for nanoscale Machines, Sensors and Robots, URL: http://www.best.cornell.edu/index.cfm/events.detail s?eventID=1257. (retrieved 15 June 2018).

Deterding, S., Otto, P., Djordevic, V. (2013). Urheberrecht und Copyright: Vergleich zweier ungleicher Brueder, in Bundeszentrale fuer Poltische Bildung, July 15, 2013, URL: http://www.bpb.de/gesellschaft/medien-undsport/urheberrecht/169971/urheberrecht-undcopyright. (retrieved 15 June 2018).

Friedrich, C.J. (1958). The philosophy of Law in Historical Perspective, University of Chicago Press, Chicago.

Heinzel, T. (2016). Designatures. Economies of Design, Politics of Participation, in $\mathrm{Na}$ (rra)tions. Essays on East and Central European Architecture, Arhitext Foundation, Bucharest.

Gilsdorf, T. (2015). Gender, Culture and Ethnomathematics, Proceedings of the Eighth International Conference on Mathematics Education and Society (MES-8), Mukhopadhyay, S. \& Greer, B. (eds.), p. 531-542.

Levy-Strauss, C. (1962). The Savage Mind, University of Chicago Press, Chicago. Translated from the French by George Weidenfield and Nicholson Ltd.

Lang, R. (2013). Sarah Morris Copyright Infringement. URL: http://www.langorigami.com/article/sarah-morriscopyright-infringement. (retrieved 15 June 2018).

Lang, R. (2018). Robert J. Lang. URL: http://www.langorigami.com/artist/robert-j-lang. (retrieved 15 June 2018). 
Lang, R. (2009). Mathematical Methods in Origami Design. Bridges 2009: mathematics, music, Art, Architecture, Culture, Banff, Canada, 26-29 July 2009, 11-20. Banff International Research Station.

Larsson, N. (2015). Inspiration or plagiarism? Mexicans seek reparations for French designer's look-alike blouse, in The Guardian, URL: https://www.theguardian.com/global-developmentprofessionals-network/2015/jun/17/mexican-mixeblouse-isabel-marant. (retrieved date: 15.06.2018).

Kachipauda, S. (2013). Mindy's Masai Mara adventure is an insult to us all, in The Guardian, URL:

https://www.theguardian.com/world/2013/sep/19/ke nya-mindy-budgor-masai-mara. (retrieved date: 15.06.2018).

Klein, U. (2005). Introduction. Technoscientific Productivity, in Perspectives on Science, Volume 13, Issue 2, Summer 2005, MIT Press, p.139-141.

Main, D. (2014). From Robots to Retinas: 9 Amazing Origami Applications, in Popular Science, URL:

Orlean, S. (2007). The Origami Lab. Why a physicist dropped everything for paper folding, in The Newyorker, $\quad$ URL: https://www.newyorker.com/magazine/2007/02/19/t he-origami-lab. (retrieved 15 June 2018).

Orfescu, C. (2016). Cris Orfescu's Biography, URL: http://crisorfescu.com/artist-biography/. (retrieved 15 June 2018).

Perner-Wilson, H. et.al. (2011). Handcrafting Textile Interfaces from A Kit-of-No-Parts, TEl'11 Conference Proceedings, Funchal, Portugal, p. 6168, DOI: $10.1145 / 1935701.1935715$.

Perner-Wilson, H. (2009). Tilt Sensing Bracelet, Instructables, http://www.instructables.com/id/Fabric-amp-BeadTilt-Sensing-Bracelet/. (retrieved 15 June 2018).

Perner-Wilson, H. (2018). Tweet from $2^{\text {rd }}$ of June $2018 . \quad$ URL: https://twitter.com/openPlusea/status/10028516939 88646912/photo/1. (retrieved 15 June 2018).

Pilling, D. (2018). Warrior tribe enlists lawyers in battle for Maasai "brand", in Financial Times, URL: https://www.ft.com/content/999ad344-fcff-11e79b32-d7d59aace167. (retrieved 15 June 2018).

Shaw, J. (1998). Convergence of Art, Science and Technology?, in Sommerer, C. \& Mignonneau, L. http://www.popsci.com/article/science/robotsretinas-9-amazing-origami-applications\#page-5. (retrieved 15 June 2018).

Mackeay (1999). Intellectual Property, in Gray, C.B. The Philosophy of Law, New York, Garland Reference Library of the Humanities.

Malina, R. (2010). What are the Different Types of Art Science Collaborations, URL: http://malina.diatrope.com/2010/08/29/what-arethe-different-types-of-art-science-collaboration/. (retrieved 15 June 2018).

Mauss, M. (1936). Les techniques du corps, Journal de Psychologie, Vol. XXXII, no. 3-4, 15 March - 15 April 1936, URL: http://classiques.uqac.ca/classiques/mauss marcel Isocio et anthropo/6 Techniques corps/Techniqu es corps.html. (retrieved 15 June 2018).

Newitz, A. (2013). 10 Physical Gestures That Have been Patented, in lo9.com. URL: https://io9.gizmodo.com/10-physical-gestures-thathave-been-patented-1251848412. (retrieved 15 June 2018).

(eds.). Art @ Science, Springer Verlag, Wien, 162166.

Simon, H. (1996). Sciences of the Artificial (3rd edition), MIT Press, Cambridge, MA.

Schneider, M. (2018). Codes of Craft and Conduct, in Kurbak, E. Stitching Worlds. Exploring Textiles and Electronics, Berlin, Revolver, p.34-43.

US Pantent 9,316,418 B2 (2016). Sensor for measuring tilt angle based on electronic textile and method thereof. URL: https://smartech.gatech.edu/bitstream/handle/1853/ 57074/9316481.pdf. (retrieved 15 June 2018) Walker, J.(2015). Our System is so Broken, Almost no Patented Discoveries Ever Get Used, in Wire, URL: https://www.wired.com/2015/01/fixing-brokenpatent-system/ (retrieved 15 June 2018).

Waloszek, G. (2012). Introduction to Design Thinking, URL: https://experience.sap.com/skillup/introduction-todesign-thinkingl. (retrieved 15 June 2018).

Weaver, C. (2011). Robert J. Lang On Origami, Sarah Morris Lawsuit, in Hyperallergic, URL: https://hyperallergic.com/25741/lang-art-origamiscience/. (retrieved 15 June 2018).

Weaver, C. (2011). Origami v. Morris. When Paper Folders Strike, in Hyperallergic, URL: https://hyperallergic.com/24731/oragami-v-morris/. (retrieved 15 June 2018). 